\title{
Triglyceride to high-density lipoprotein cholesterol ratio predicts all- cause and cardiovascular mortality in diabetic patients with coronary artery disease on statin treatment
}

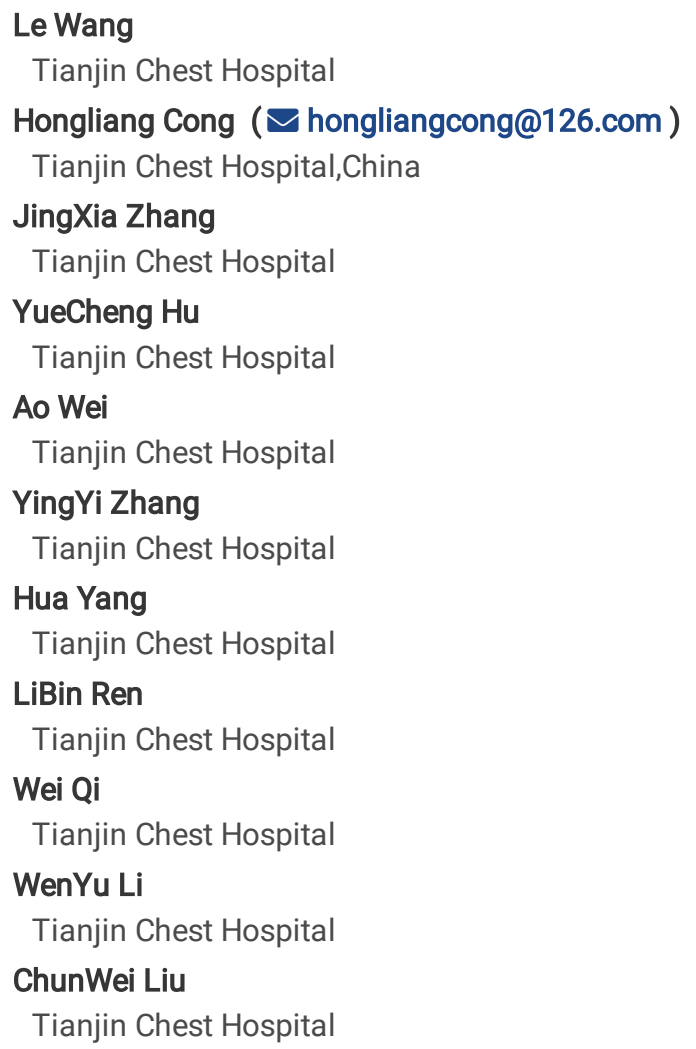




\section{Abstract \\ Background}

The triglyceride (TG)to high-density lipoprotein cholesterol (HDL-C) ratio has been regarded as an independent predictor of cardiovascular events. However, the association of TG/HDL-C ratio with survival in patients with diabetes and coronary artery disease (CAD) on statin therapy remains uncertain. The aim of the present study was to explore whether TG/HDL-C ratio predicts mortality in diabetic patients with CAD on statin treatment.

\section{Methods}

A total of 2080 consecutive patients with type 2 diabetes and angiographic-proven CAD who were treated with statin were enrolled in the presents study. Patients were divided into tertiles according to baseline TG/HDL-C ratio. The primary endpoints were all-cause and cardiovascular mortality.

\section{Results}

During 4-year follow-up, 209(10.0\%) patients died, 136(65.1\%) caused by cardiovascular disease (CVD). The Kaplan-Meier analyses showed that all-cause and cardiovascular mortality increased gradually with rising TG/HDL-C ratio tertiles (log-rank test, $\mathrm{P}<0.001$, respectively). Multivariate cox hazard regression analysis revealed that patients in tertile 3 but not teretile 2 had significantly higher rate of all-cause and cardiovascular mortality $(\mathrm{P}<0.001, \mathrm{P}<0.05$, respectively). Moreover, TG/HDL-C ratio was independently associated with all-cause mortality (HR: 1.21, 95\% Cl:1.11-1.31; P< 0.001) and cardiovascular mortality (HR:1.28, 95\% Cl: 1.19-1.37; P< 0.001). For all-cause mortality, TG/HDL$C$ ratio significantly improved the $C$-statistic $(0.799[0.766-0.833]$ to $0.813[0.780-0.845] ; P=0.018)$, net reclassification index $(\mathrm{NRI})(0.315 ; \mathrm{P}$ $<0.001)$, and integrated discrimination index (IDI) $(0.012 ; \mathrm{P}=0.003)$. For cardiovascular mortality, TG/HDL-C ratio significantly improved the C-statistic (0.769[0.727-0.812] to 0.810[0.771-0.849]; $P=0.001)$, NRI $(0.442 ; P<0.001)$, and IDI $(0.039 ; P<0.001)$.

\section{Conclusions}

TG/HDL-C ratio may predict mortality risk among diabetic CAD patients receiving statin treatment. These findings suggest that assessing TG/HDL-C ratio may be useful for risk stratification for mortality risk in patients with diabetes and CAD.

\section{Background}

Diabetes mellitus (DM) is an independent risk factor for coronary artery disease (CAD)[1]. Numerous studies have demonstrated that statin therapy significantly reduce cardiovascular events in patients with DM[2-5]. More than one-quarter of patients with CAD are combined with Type 2 DM(T2DM). Despite the wide use of statin, patients with T2DM and CAD remain at higher risk of mortality compared with those without diabetes, part of which results from abnormal lipoprotein and lipid levels[6]. Therefore, it is necessary that lipid status be reassessed in patients with T2DM and CAD on statin treatment to identify those with higher residual risk so that tailored risk reduction strategies can be provided.

Dyslipidemia is characterized by higher triglyceride (TG) levels, lower high-density lipoprotein cholesterol (HDL-C) levels and increased small dense high-density lipoprotein cholesterol(sd-LDL) particles in patients with T2DM[7, 8]. It has been demonstrated that elevated serum TG and reduced HDL-C levels contribute to poor prognosis in patients with T2DM[9-12]. However, TG and HDL-C levels alone do not reflect the actual status of plasma atherogenicity and cardiovascular disease (CVD) risk[13]. The TG/HDL-C ratio,which may reflect TG and HDL-C simultaneously, has been considered as a marker of plasma atherogenicity[14]. Moreover, TG/HDL-C ratio can be a better predictor for insulin resistance (IR) [15-17], which can reflect the degree of abnormal glucose metabolism. Numerous studies have shown a positive association between the TG/HDL-C ratio and cardiovascular risk factors, including hypertension[18-20], obesity[21], metabolic syndrome[22-24], hyperuricemia[25], nonalcoholic fatty liver disease[26, 27]. A high TG/HDL-C ratio is also correlated with increased arterial stiffness[28, 29], impaired heart rate recovery after exercise [30]and increased carotid atherosclerosis[31]. Furthermore, TG/HDL-C ratio is a good predictor of risk for cardiovascular events[32-34], all-cause and cardiovascular death[35] among healthy individuals and those with cardiovascular risk factors. Recent data suggested that higher TG/HDL-C ratio is associated with poor CAD-related prognosis[36-43]. High TG/HDL-C ratio is significantly associated with increased incidence of T2DM[44-48]. Moreover, TG/HDL-C ratio is also associated with increased incidence of macrovascular and microvascular complications in patients with T2DM, independently of potential confounders[49]. All these suggest that it may be plausible to use TG/HDL-C ratio as a predictor of future cardiovascular risk in patients withT2DM and CAD.

Page 2/15 
However, it is still controversial whether TG/HDL-C ratio may predict cardiovascular events in patients with diabetes[50, 51]. To date, the prognostic significance of TG/HDL-C ratio in patients with T2DM and CAD on statin treatment is unclear. Therefore, we sought to determine the association of TG/HDL-C ratio with all-cause and cardiovascular mortality in patients with T2DM and CAD.

\section{Methods}

\section{Study population}

The present study was a single-center, retrospective, observational cohort study. From January 2016 to September 2016 , a total of 2678 consecutive patients with Type 2 DM and CAD who were admitted to Tianjin Chest Hospital for coronary artery angiography because of angina-like chest pain were enrolled in this study. DM was diagnosed by fasting plasma glucose (FPG) $\geq 7.0 \mathrm{mmol} / \mathrm{L}$ or a $2-\mathrm{h}$ plasma glucose level on their oral glucose tolerance test (OGTT) $\geq 11.1 \mathrm{mmol} / \mathrm{L}$, hemoglobin $\mathrm{A} 1 \mathrm{c}(\mathrm{HbA} 1 \mathrm{c}) \geq 6.5 \%$ or currently using insulin or hypoglycemic medications. The result of coronary angiography (CAG) showed at least one major coronary artery diameter stenosis $\geq 50 \%$ was diagnosed as CAD. The CAD included stable angina pectoris (SAP) and acute coronary syndrome (ACS). ACS was defined as including either unstable angina pectoris (UAP), non-ST-segment elevation myocardial infarction (NSTEMI), or ST-segment elevation myocardial infarction (STEMI). We included only those treated with statin during hospitalization. Those patients with the following characteristics were excluded: (1) younger than 18 or older than $80(n=72) ;(2)$ severe valvular heart disease or severe congenital heart disease requiring cardiac surgery $(n=34) ;(3)$ sever liver dysfunction (defined as alanine aminotransferase $>3$ times the normal upper limit) ( $n=15)$ or severe kidney dysfunction (defined as serum creatinine> 1.5 times the normal upper limit )( $n=96)$; (4)hyperthyroidism, hypothyroidism( $n=16) ;(5)$ those lacking complete clinical data $(n=75) ;(6)$ those who did not receive statin treatment during hospitalization( $n=99)$. A total of 2271 patients participated in the research. Patients were followed up from January 2020 to September 2020 by telephone or outpatient clinical visit, and 2080 (91.6\%) patients completed the 4-year clinical follow-up. The patients were divided into tertiles according to the admission TG/HDL-C

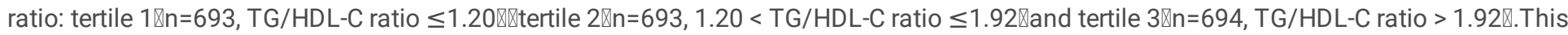
study was approved by the local research ethics committee and strictly adhered to the Declaration of Helsinki. Given the retrospective nature of the present research, no informed consent was required.

\section{Data collection and definition}

Clinical data were collected from all of the medical records by trained clinicians who were blinded to the purpose of the study. The data included age, gender, duration of diabetes, whether diabetes had been newly diagnosed, smoking history, history of hypertension, previous myocardial infarction (MI), previous percutaneous coronary intervention (PCI), previous coronary artery bypass graft (CABG), previous stroke, height, weight, left ventricle ejection fraction (LVEF) and medication at discharge. Peripheral venous blood samples were collected early in the morning after an overnight fast on admission and analyzed shortly after sampling. FPG, HbA1c, total cholesterol (TC), TG, low-density lipoprotein cholesterol (LDL-C), HDL-C, serum creatinine, serum uric acid and high-sensitivity C-reactive protein (hs-CRP) were analyzed. Renal function was assessed using the baseline estimated glomerular filtration rate (eGFR). Body mass index (BMI) was defined as weight $(\mathrm{kg}) /$ height $\left(\mathrm{m}^{2}\right)$. All of the patients underwent coronary angiography during this hospitalization. Significant stenosis was defined as $\geq 50 \%$ diameter stenosis in at least one major coronary artery and multivessel disease was defined as $\geq 2$ vessels with significant stenosis as observed during angiography.

\section{Study endpoints}

The endpoints were all-cause and cardiovascular mortality. All-cause mortality was defined as death from any cause. Cardiovascular mortality was defined as death related to acute $\mathrm{Ml}$, congestive heart failure, malignant arrhythmia, or stroke.

\section{Statistical analysis}

Continuous variables were expressed as mean \pm standard deviation when normally distributed, and as medians with interquartile ranges for results not normally distributed. Categorical variables were presented as frequencies. Baseline demographic characteristics, clinical presentation, laboratory findings, extent of CAD, revascularization, and medication data were compared between groups using analysis of variance or Kruskal-Wallis tests for continuous variables, and with chi-square test or Fisher's exact test for categorical variables. The eventfree survival rates among groups were calculated by using the Kaplan-Meier method and the log-rank test. The association of TG/HDL-C ratio with all-cause and cardiovascular mortality was evaluated by multivariate Cox proportional hazard models. Hazard rations (HRs) and 95\% confidence interval $(\mathrm{Cl})$ were calculated for TG/HDL-C ratio as a group variable with the lowest TG/HDL-C ratio tertiles as reference category. Four adjusted models were used. Model 1 was adjusted for age, male, duration of diabetes, smoker, hypertension, previous MI, previous PCl, previous CABG, previous stroke, BMI. Model 2 was adjusted for model 1 covariates plus LVEF, ACS, left main disease, multi-vessel disease, treatment. Model 3 was adjusted for model 2 covariates plus FPG, HbA1c, TC, LDL, Uric acid, hs-CRP, eGFR. Model 4 was adjusted for model 
3 covariates plus aspirin, clopidogrel/ticagrelor, $\beta$-blocker, angiotensin II coenzyme inhibitor(ACEI)/ angiotensin II receptor blocker(ARB), calcium channel blocker(CCB), nitrate, insulin. Sensitivity analysis was further performed to clarify the association of TG/HDL-C ratio with mortality. To evaluate whether an increased TG/HDL-C ratio had incremental predictive value for mortality, C-statistics, net reclassification improvement (NRI), and integrated discrimination improvement (IDI) were compared between models. The area under the receiver operating characteristic (ROC) curves was used to indicate the predictive value of the TG/HDL-C ratio for mortality. All-cause and cardiovascular mortality were also assessed in several subgroups and the possible interaction between TG/HDL-C ratio and the specific subgroup. A 2-sided analysis with a P value $<0.05$ was considered significant. All analyses were performed using SPSS version 20.0 (IBM Corp, Armonk, New York) and SAS version 9.1.3 (Cary, NC, USA).

\section{Results}

\section{Patient's Baseline Characteristics}

The baseline characteristics of the study population according to TG/HDL-C ratio tertiles were presented in Table1. A total of 2080 patients were included in the study. The mean age was $66.2 \pm 6.8$ years, the mean duration of DM was $9.7 \pm 7.7$ years, $1167(56.1 \%)$ patients were males,913(43.9\%) patients were female, 821(39.5\%) patients had a history of smoking, 1585(76.2\%) patients had hypertension, 257(12.4\%) patients had history of $\mathrm{MI}, 434(20.9 \%)$ patients had history of stroke, $415(20.0 \%)$ patients had history of $\mathrm{PCl}$, and $81(3.9 \%)$ patients had history of CABG. Baseline TG/HDL-C ratio ranged from 0.25 to 18.84 in the study cohort. The mean levels of TG/HDL-C ratio of the three groups were $0.88 \pm 0.21,1.54 \pm 0.20,3.09 \pm 1.62$,respectively. There were significant differences $(P<0.05)$ among the three groups in terms of $\mathrm{BMI}, \mathrm{HbA1c}, \mathrm{TC}, \mathrm{TG}, \mathrm{HDL}-\mathrm{C}$, uric acid, hs-CRP and eGFR. While there were no significant differences among the three groups in terms of age, male, duration of DM, smoker, hypertension, previous MI, previous stroke, previous PCl, previous CABG, LVEF, clinical presentation, left main disease, multi-vessel disease ,treatment strategy, FBG ,LDL-C and the use of medications at discharge including aspirin, clopidogrel or ticagrelor, $\beta$-blocker, ACEI/ARB, CCB, nitrate and insulin.

\section{TG/HDL-C ratio and mortality}

During 4-year follow-up, 209(10.0\%) patients died, 136(65.1\%) caused by cardiovascular disease (CVD). All-cause mortality across TG/HDL-C ratio tertile groups were $6.6 \%, 10.1 \%, 13.4 \%$, respectively. Cardiovascular mortality across TG/HDL-C ratio tertile groups were $3.9 \%, 6.2 \%$, $9.5 \%$, respectively. As shown in Figure1 and Figure 2, Kaplan-Meier survival analysis showed that the cumulative incidence of all-cause and cardiovascular mortality significantly increased with higher TG/HDL-C ratio tertiles (log-rank test, $\mathrm{P}<0.001$, respectively).

As shown in Table2, patients in TG/HDL-C ratio tertile 2 had a 1.54-fold higher risk, while those in tertile 3 had a 2.09-fold higher risk of allcause moratlity in the crude model compared with the reference group (TG/HDL-C ratio tertile1). After adjustment for other potential covariates, patients in TG/HDL-C ratio tertile 3 remained had significantly higher risk of all-cause mortality while no significant difference was observed for those with tertile 2 compared with TG/HDL-C ratio tertile1 group. For cardiovascular mortality, patients in TG/HDL-C ratio tertile 2 had a 1.98-fold higher risk, while those in tertile 3 had a 2.45 -fold higher risk in the crude model compared with the reference group (TG/HDL-C ratio tertile1). After adjustment for other potential covariates, patients in TG/HDL-C ratio tertile 3 remained had significantly higher risk of cardiovascular mortality while no significant difference was observed for those with tertile 2 compared with TG/HDL-C ratio tertile1 group. Multivariate cox hazard regression analysis showed that TG/HDL-C ratio remained to be an independent predictor of all-cause and cardiovascular mortality as a continuous variable (HR: 1.21, 95\% Cl: 1.11-1.31, P<0.001; HR: 1.28, 95\% Cl: 1.19-1.38, $\mathrm{P}<0.001$, respectively). As shown in Table3, the significant association between TG/HDL-C ratio and mortality remained unchanged in a sensitivity analysis in which each of the other significant covariates in univariate analysis was forced into the model with continuous TG/HDL-C ratio (per 1-SD increase).

The ROC analysis showed that the optimal cutoff value of the TG/HDL-C ratio for predicting all-cause mortality was 1.77 (sensitivity $53.1 \%$ and specificity $62.8 \%$ ), with an area under the curve (AUC) of 0.601 (95\% Cl: 0.561-0.640, P<0.001).Adding TG/HDL-C ratio to the model of established risk factors including age, previous PCI, LVEF, left main disease, multi-vessel disease, FBG and eGFR improved the prediction of all-cause mortality in C-statistic (from 0.799 to $0.813, \mathrm{P}=0.018$ ), and also a significant increase in NRI $(0.315,95 \% \mathrm{Cl}: 0.175-0.457, \mathrm{P}<0.001$ ) and IDI $(0.012,95 \% \mathrm{Cl}: 0.004-0.021, \mathrm{P}=0.003)$. The ROC analysis showed that the optimal cutoff value of the TG/HDL-C ratio for predicting cardiovascular mortality was 1.57 (sensitivity $74.3 \%$ and specificity $53.8 \%$ ), with an area under the curve (AUC) of 0.672 (95\% Cl: $0.625-0.718$, $\mathrm{P}<0.001)$.

Adding TG/HDL-C ratio to the model of established risk factors including age, previous PCI, LVEF, left main disease, multi-vessel disease, FBG and eGFR improved the prediction of cardiovascular mortality in C-statistic (from 0.769 to $0.810, P=0.001$ ), and also a significant increase in NRI $(0.442,95 \% \mathrm{Cl}: 0.270-0.613, \mathrm{P}<0.001)$ and IDI $(0.039,95 \% \mathrm{Cl}: 0.023-0.055, \mathrm{P}<0.001)$. 


\section{Subgroup analysis}

All-cause and cardiovascular mortality were assessed in subgroups obtained by dichotomizing patients according to sex, smoker, BMI (cutoff value, $28 \mathrm{~kg} / \mathrm{m}^{2}$ ), duration of DM (cut-off value, 10 years), ACS, HbA1c (cut-off value, 7.0), LDL-C (cut-off value, 1.8), insulin treatment and revascularization. For this analysis, TG/HDL-C ratio was dichotomized according to the optimal cutoff values for all-cause and cardiovascular mortality. The relationship of TG/HDL-C ratio with all-cause mortality or cardiovascular mortality was relatively consistent across the subgroups. There were no significant interactions between TG/HDL-C ratio and these variables.

\section{Discussion}

Even though TG/HDL-C ratio has been regarded as a marker of plasma atherogenicity and an independent predictor of cardiovascular events, the potential role of TG/HDL-C ratio in predicting mortality risk in patients with $\mathrm{DM}$ and CAD who are treated with statin has not been determined. As far as our knowledge, the present study is the first study to investigate the prognostic value of TG/HDL-C ratio in patients with DM and CAD in the era of statin therapy. In this study, we demonstrated that higher TG/HDL-C ratio was associated with increased risk of allcause and cardiovascular mortality. After adjusting for both established risk factors for $\mathrm{CV}$ disease and other prognostic biomarkers, TG/HDL-C ratio remained an independent predictor of all-cause and cardiovascular mortality. The significant association of TG/HDL-C ratio with mortality was further confirmed by sensitivity analysis. Furthermore, adding TG/HDL-C ratio to the established model exhibited a significant enhancement on the performance of predicting mortality. TG/HDL-C ratio predicted an increased risk of all-cause and cardiovascular mortality across a wide range of subgroups of patients with DM and CAD. These results are important in that they provide important information about the unique association between TG/HDL-C ratio and mortality in diabetic patients with CAD treated with statin. All these suggested that TG/HDL-C ratio is a marker for poor prognosis even in the era of statin treatment that contribute to early identification of high-risk patients with DM and CAD. Furthermore, routine TG/HDL-C ratio calculation may further improve risk stratification for mortality risk.

It has been demonstrated that LDL-C plays a key role in the development and progression of atherosclerotic cardiovascular disease (ASCVD) and statin is the first-line therapy for lowering LDL-C levels to reduce ASCVD risk. However, patients with DM and CAD remain suffer from ongoing cardiovascular risk even if LDL-C achieves the targeted goals, which indicates that there are residual cardiovascular risk factors other than LDL-C. Therefore, the classic lipid-metabolic indicator (LDL-C) cannot completely explain the poor prognosis in diabetic patients. There is evidence that statin-treated patients with DM have a high prevalence of persistent atherogenic dyslipidemia[13]. Elevated TG levels and reduced HDL-C levels, as typic lipid feature of diabetes, have been considered as potently atherogenic dyslipidemia in patients with DM[52, 53]. However, because TG and HDL-C are mutually independent risk factors, their levels alone do not reflect the actual status of plasma atherogenicity and CVD risk in the absence of IR[13]. The most relevant cases which has with potent atherogenic effect are those with concurrent elevated TG levels and reduced HDL-C levels. Thus, TG/HDL-C ratio, as an indicator reflecting TG and HDL-C simultaneously, has been regarded as a good marker for CVD in primary and secondary prevention[34,39]. Moreover, recent findings suggested that the combination of TG and HDL-C in the form of a ratio has better predictive value for mortality than individual cholesterol risk factors[54]. It is well established that TG/HDL-C ratio is positively associated with the risk of T2DM risk[44-48]. Elevated TG/HDL-C ratios is also associated with increased risk of CAD in patients with T2DM independent of the baseline LDL-C levels[49]. Furthermore, high TG/HDL-C ratio may strongly predict the extent of coronary lesion[ $[55,56]$. In statin-treated diabetic patients, TG/HDL-C ratio, as opposed to LDL-C levels, is associated with vulnerable plaque features evaluated by frequency-domain optical coherence tomography (FD-OCT)[57]. While diabetes is a major risk factor for $C A D$, not all patients with diabetes and CAD have an equal cardiovascular risk. Routine lipid examinations do not reflect the actual compositional changes of lipid parameters in patients with DM and CAD. Therefore, evaluation of TG/HDL-C ratio may have great clinical significance on risk stratification for patients with T2DM and CAD on statin treatment.

Previous studies have addressed the prognostic role of TG/HDL-C ration in patients with CAD. Studies from wan et al .and Dai et al. demonstrated that elevated TG/HDL-C ratio was associated with an increased risk of all-cause mortality in CAD patients after PCI[37, 42]. Findings from Matsumoto et al revealed that in statin-treated patients, nonfasting TG/HDL-C ratio was a valuable predictor for cardiovascular events after PCI[39]. Sultani et al revealed that elevated TG/HDL-C ratio may predict long-term all-cause mortality and major adverse cardiac event (MACE) in high-risk patients undergoing coronary angiography[40]. Bitter et al. found that after adjusting for conventional cardiovascular risk factors and coronary disease severity, TG/HDL-C ratio was a powerful independent predictor of all-cause mortality and cardiovascular events in women with suspected ischemia, but without obstructive plaque on angiography[36]. Prasad et al. reported that TG/HDL-C predicts adverse cardiovascular events in women with non-obstructive CAD [41]. All these findings suggest that using TG/HDL-C ratio may help predict poor cardiovascular outcomes in patients with CAD regardless of the severity of coronary artery stenosis and potential sex-specific difference in the prognostic value of TG/HDL-C ratio may exist. Calculation TG/HDL-C ratio is useful for identification of those at high future cardiovascular risk in CAD patients. However, there are significant limitations in few studies that assess 
the association between TG/HDL-C ratio and cardiovascular events given the small sample size, gender-specific and pre-selected CAD patients. Furthermore, the incremental prognostic value of TG/HDL-C ratio beyond traditional risk factors was not well investigated.

Besides, it is controversial whether TG/HDL ratio is able to predict cardiovascular risk in patients with established DM. In the Swedish National Diabetes Register (NDR) study of 54,061 patients with 4.8 years follow-up, obese T2DM patients with elevated TG/HDL-C ratio significantly increased the risk of CVD independent of LDL-C levels[58]. In a Chinese cohort of 1,447 type 2diabetic patients with angiographic-proven stable CAD with an average of 20.3 months follow-up, Yang et al. found that TG/HDL-C ratio was a significant predictor of cardiovascular events defined as the composite of cardiac death, stroke, nonfatal MI and post-discharge revascularization in patients with diabetes and stable CAD after adjustment for multiple traditional risk factors of CVD[50]. Contrary to these studies, a few other studies failed to demonstrated the association between TG/HDL-C ratio and adverse cardiovascular events in patients with diabetes. A study of 1021 diabetic patients who were followed up for 8.6 years showed that the value of TG/HDL-C ratio was significantly higher in patients with cardiovascular events than those without cardiovascular events. However, the association between TG/HDL-C ratio and cardiovascular events was not significant after multivariate cox hazard regression analysis[59]. In congruent with this study, the sub analysis of the Management of Elevated Cholesterol in the Primary Prevention Group of Adult Japanese (MEGA) study including 668 patients with DM and without history of CVD could not demonstrate the independent association between TG/HDL ration and cardiovascular events over a mean follow-up period of 5.3 years[51]. Discrepancies among the aforementioned studies might due to differences in population studied, event definition and length of follow-up. It is important to note that none of the previous studies considered whether the use of statin modify the prognostic value of TG/HDL-C ratio in patients with DM.

To the best of our knowledge, the present study is the first to focus on patients with T2DM and angiography-proven CAD on statin treatment. Compared with previous studies focusing on CAD patients, our large cohort study included higher risk of patients who had a higher percentage of history of CVD. Moreover, patients in our study underwent non-invasive or invasive treatment. It is important to assess data from patients who underwent non-invasive and invasive treatment because this reflects the reality of our clinical practice. Except for the CVD risk factors, the severity of CAD, the cardiac function, the kidney function, blood glucose levels and medication use in the present study were also adjusted in the multivariable analysis. Consistent with previous studies, our study demonstrated that elevated TG/HDL-C ratio was associated with poor prognosis in patients with T2DM and CAD. After adjustment for relevant clinical and laboratory covariates, elevated TG/HDL-C remained a significant and independent predictor of all-cause and cardiovascular mortality. Moreover, TG/HDL-C ratio predicted an increased risk of all-cause and cardiovascular mortality across all subsets of patients. Even in patients with LDL-C levels $\leq 1.80 \mathrm{mmol} / \mathrm{L}$, elevated TG/HDL-C ratio was still associated with the increased risk of mortality, suggesting TG/HDL-C ratio may explain part of residual risk and TG/HDL-C ratio may show predictive value for adverse prognosis regardless of level of LDL-C. The TG/HDL-C ratio also showed predictive values for mortality in patients with $\mathrm{HbA1c}>7.0$ and $\leq 7.0$, which indicated that there is no significant interaction between glycometabolic status and TG/HDL-C ratio on risk prediction. There were also no significant interactions between TG/HDL-C ratio and other variables including sex, smoking, BMI, ACS, duration of DM, insulin treatment and revascularization. Therefore, our study extended the positive association between TG/HDL-C ratio and cardiovascular risk in patients with $\mathrm{DM}$. The use of statin has less impact on the prognostic value of TG/HDL-C ratio in patients with established DM.

Meanwhile, we assessed the incremental value of TG/HDL-C ratio into a risk prediction model for mortality in terms of C-statistic value, NRI and IDI. The TG/HDL-C ratio showed significant improvement in risk prediction and risk reclassification for all-cause and cardiovascular mortality. To the best of our knowledge, the present study demonstrated, for the first time, that TG/HDL-C ratio may refine risk stratification for mortality. Routinely calculated the TG/HDL-C ratio might be useful for identification of those with higher future cardiovascular risk. Our results add new evidence for the predictive value of TG/HDL-C ratio for patients with CAD. Although previous studies revealed that elevated TG/HDL-C ratio increased CVD risk, the cut-off value of TG/HDL-C ratio to predict CVD risk in secondary prevention has not been well established. We identified 1.77 and 1.57 as the optimal cut-off points of TG/HDL-C ratio to predict the risk of all-cause and cardiovascular mortality. This indicated that it is desirable to ensure the TG/HDL-C ratio is not higher than the optimal cut-off points to improve prognosis. More attention should be given to the management of cardiovascular risk in patients with higher TG/HDL-C ratios. Our results provide novel evidence for the prognostic utility of elevated TG/HDL-C ratio in patients with DM treated with statin.

Several potential mechanisms may account for the association TG/HDL-C ratio with all-cause and CV mortality in patients with T2DM and CAD. First, TG/HDL-C ratio, as a proxy for atherogenic dyslipidemia, reflects the complex interaction between atherogenic and protective lipoprotein. Elevated TG level and decreased HDL-C content may directly contribute to endothelial dysfunction and atherosclerosis.

Furthermore, elevated TG/HDL-C ratio is positively associated with other atherogenic lipid phenotype, characterized by higher small dense LDL particles [14, 60]along with higher remnant particle cholesterol and non-HDL-C [61]which contribute to progression of atherosclerosis. Second, elevated TG/HDL-C ratio is associated with worsening IR in patients with diabetes[15, 16]. It is well known that IR is related to the development and accelerated progression of atherosclerosis, vulnerability of coronary plaques and risk of adverse outcomes in patients with CAD. Moreover, elevated TG/HDL-C ratio is associated with poor glycemic control in diabetic patients[62]. A hyperglycemic environment may 
contribute to the development of macrovascular and microvascular disease in patients with T2DM, such as diabetic nephropathy, CAD, cerebrovascular disease and peripheral artery disease, all of the conditions known to increase the risk of mortality. Although the exact mechanism needs to be further elucidated, the association between TG/HDL-C ratio and mortality has practical implications in patients with T2DM and CAD treated with statin.

Nonetheless, there are some limitations in the present study. Firstly, owing to the retrospective and observational nature of the present study, it is difficult to exclude influence from some unmeasured factors. Unmeasured factors such as diabetes complication may have exaggerated the results of this study. Secondly, lipid levels and other parameters were only examined at admission, therefore, it is not known whether timevarying TG/HDL-C ratio could predict mortality. Thirdly, data of follow-up statin use and other non-statin lipid-lowering agents were not available that could potentially impact the association between TG/HDL-C ratio and mortality. Future prospective studies are required to verify our conclusions. Last but not least, TG/HDL-C ratios are known to vary with ethnicity, which may limit the generalization of these results. Despite these limitations, the present study has important clinical significance because it is the first study to investigate the association between TG/HDL-C ratio and mortality in patients with T2DM and CAD treated with statin.

\section{Conclusions}

An elevated TG/HDL-C ratio may predict all-cause and cardiovascular mortality risk in diabetic patients with CAD on statin treatment. The prognostic value provided by TG/HDL-C ratio is incremental to the information provided by established risk factors. These findings suggest that assessment of TG/HDL-C ratio should be routinely included for all-cause and cardiovascular mortality risk assessment.

\section{Abbreviations}

CAD: Coronary artery disease; DM: Diabetes mellitus; T2DM: Type 2 DM; TG: Triglyceride; HDL-C: High density lipoprotein-C; sd-LDL: small dense high-density lipoprotein cholesterol; CVD: cardiovascular disease; IR: insulin resistance; FPG: fasting plasma glucose; OGTT: oral glucose tolerance test; HbA1c: hemoglobin A1c; CAG: coronary angiography; SAP :stable angina pectoris; ACS: acute coronary syndrome; UAP: unstable angina pectoris; NSTEMI: non-ST-segment elevation myocardial infarction; STEMI:ST-segment elevation myocardial infarction; MI: myocardial infarction; PCl: percutaneous coronary intervention; CABG: previous coronary artery bypass graft; LVEF: left ventricle ejection fraction; hs-CRP: high-sensitivity C-reactive protein; TC: total cholesterol; LDL-C: low-density lipoprotein cholesterol; eGFR: estimated glomerular filtration rate; BMI: body mass index; HRs: hazard rations; Cl: confidence interval; ACEl: angiotensin II coenzyme inhibitor; ARB: angiotensin II receptor blocker; CCB: calcium channel blocker; NRI: net reclassification improvement; IDI: integrated discrimination improvement; ROC: receiver operating characteristic; AUC: area under the curve; ASCVD: atherosclerotic cardiovascular disease; MACE: major adverse cardiac event; NDR: National Diabetes Register ; MEGA :Management of Elevated Cholesterol in the Primary Prevention Group of Adult

\section{Declarations}

\section{Acknowledgements}

We thank all the investigators and subjects who participated in this project.

\section{Authors' contributions}

LW, HLC and JXZ participated in the study design. LW, YCH, AW, YYZ, HY, LBR, WQ, WYL and CWL participated in data collection. LW, HY and LBR performed the statistical analysis. LW drafted the article. All authors read and approved the final manuscript.

\section{Funding}

This study was supported by Tianjin Science and Technology Committee (17ZXMFSY00020).

\section{Availability of data and materials}

The datasets used and/or analyzed during the current study are available from the corresponding author on reasonable request.

\section{Ethics approval and consent to participate}

The study was approved by our local ethical committee. No informed consent was required.

\section{Consent for publication}


Not applicable.

Competing interests

The authors declare that they have no competing interests.

\section{References}

1. Norhammar A, Malmberg K, Diderholm E, Lagerqvist B, Lindahl B, Ryden L, Wallentin L: Diabetes mellitus: the major risk factor in unstable coronary artery disease even after consideration of the extent of coronary artery disease and benefits of revascularization. $J$ Am Coll Cardiol 2004, 43(4):585-591.

2. Colhoun HM, Betteridge DJ, Durrington PN, Hitman GA, Neil HA, Livingstone SJ, Thomason MJ, Mackness MI, Charlton-Menys V, Fuller $\mathrm{JH}$ et al: Primary prevention of cardiovascular disease with atorvastatin in type 2 diabetes in the Collaborative Atorvastatin Diabetes Study (CARDS): multicentre randomised placebo-controlled trial. Lancet 2004, 364(9435):685-696.

3. Sever PS, Poulter NR, Dahlof B, Wedel H, Collins R, Beevers G, Caulfield M, Kjeldsen SE, Kristinsson A, Mclnnes GT et al: Reduction in cardiovascular events with atorvastatin in 2,532 patients with type 2 diabetes: Anglo-Scandinavian Cardiac Outcomes Trial-lipidlowering arm (ASCOT-LLA). Diabetes Care 2005, 28(5):1151-1157.

4. Knopp RH, d'Emden M, Smilde JG, Pocock SJ: Efficacy and safety of atorvastatin in the prevention of cardiovascular end points in subjects with type 2 diabetes: the Atorvastatin Study for Prevention of Coronary Heart Disease Endpoints in non-insulin-dependent diabetes mellitus (ASPEN). Diabetes Care 2006, 29(7):1478-1485.

5. Tajima N, Kurata H, Nakaya N, Mizuno K, Ohashi Y, Kushiro T, Teramoto T, Uchiyama S, Nakamura H, Primary Prevention Group of Adult Japanese S: Pravastatin reduces the risk for cardiovascular disease in Japanese hypercholesterolemic patients with impaired fasting glucose or diabetes: diabetes subanalysis of the Management of Elevated Cholesterol in the Primary Prevention Group of Adult Japanese (MEGA) Study. Atherosclerosis 2008, 199(2):455-462.

6. Rawshani A, Rawshani A, Franzen S, Sattar N, Eliasson B, Svensson AM, Zethelius B, Miftaraj M, McGuire DK, Rosengren A et al: Risk Factors, Mortality, and Cardiovascular Outcomes in Patients with Type 2 Diabetes. N Engl J Med 2018, 379(7):633-644.

7. Verges B: Pathophysiology of diabetic dyslipidaemia: where are we?Diabetologia 2015, 58(5):886-899.

8. Filippatos T, Tsimihodimos V, Pappa E, Elisaf M: Pathophysiology of Diabetic Dyslipidaemia. Curr Vasc Pharmacol 2017, 15(6):566-575.

9. Chan WB, Tong PC, Chow CC, So WY, Ng MC, Ma RC, Osaki R, Cockram CS, Chan JC: Triglyceride predicts cardiovascular mortality and its relationship with glycaemia and obesity in Chinese type 2 diabetic patients. Diabetes Metab Res Rev 2005, 21(2):183-188.

10. Joo HJ, Cho SA, Hong SJ, Hur SH, Bae JH, Choi DJ, Ahn YK, Park JS, Choi RK, Choi D et al: Impact of low high-density lipoproteincholesterol level on 2-year clinical outcomes after acute myocardial infarction in patients with diabetes mellitus. Lipids Health Dis 2016, 15(1):197.

11. Li XL, Hong LF, Luo SH, Guo YL, Zhu CG, Sun J, Dong Q, Qing P, Xu RX, Liu J et al: Impact of admission triglyceride for early outcome in diabetic patients with stable coronary artery disease. Lipids Health Dis 2014, 13:73.

12. Ogita M, Miyauchi K, Miyazaki T, Naito R, Konishi H, Tsuboi S, Dohi T, Kasai T, Yokoyama T, Okazaki S et al: Low high-density lipoprotein cholesterol is a residual risk factor associated with long-term clinical outcomes in diabetic patients with stable coronary artery disease who achieve optimal control of low-density lipoprotein cholesterol. Heart Vessels 2014, 29(1):35-41.

13. Quispe R, Martin SS, Jones SR: Triglycerides to high-density lipoprotein-cholesterol ratio, glycemic control and cardiovascular risk in obese patients with type 2 diabetes. Curr Opin Endocrinol Diabetes Obes 2016, 23(2):150-156.

14. Yokoyama K, Tani S, Matsuo R, Matsumoto N: Increased triglyceride/high-density lipoprotein cholesterol ratio may be associated with reduction in the low-density lipoprotein particle size: assessment of atherosclerotic cardiovascular disease risk. Heart Vessels 2019 , 34(2):227-236.

15. Ren X, Chen ZA, Zheng S, Han T, Li Y, Liu W, Hu Y: Association between Triglyceride to HDL-C Ratio (TG/HDL-C) and Insulin Resistance in Chinese Patients with Newly Diagnosed Type 2 Diabetes Mellitus. PLoS One 2016, 11(4):e0154345.

16. Zhou M, Zhu L, Cui X, Feng L, Zhao X, He S, Ping F, Li W, Li Y: The triglyceride to high-density lipoprotein cholesterol (TG/HDL-C) ratio as a predictor of insulin resistance but not of beta cell function in a Chinese population with different glucose tolerance status. Lipids Health Dis 2016, 15:104.

17. Uruska A, Zozulinska-Ziolkiewicz D, Niedzwiecki P, Pietrzak M, Wierusz-Wysocka B: TG/HDL-C ratio and visceral adiposity index may be useful in assessment of insulin resistance in adults with type 1 diabetes in clinical practice. J Clin Lipidol 2018, 12(3):734-740.

18. Liu D, Guan L, Zhao Y, Liu Y, Sun X, Li H, Yin Z, Li L, Ren Y, Wang B et al: Association of triglycerides to high-density lipoproteincholesterol ratio with risk of incident hypertension. Hypertens Res 2020, 43(9):948-955.

Page 8/15 
19. Yeom H, Kim HC, Lee JM, Jeon Y, Suh I: Triglyceride to high density lipoprotein cholesterol ratio among adolescents is associated with adult hypertension: the Kangwha study. Lipids Health Dis 2018, 17(1):212.

20. Tohidi M, Hatami M, Hadaegh F, Azizi F: Triglycerides and triglycerides to high-density lipoprotein cholesterol ratio are strong predictors of incident hypertension in Middle Eastern women. J Hum Hypertens 2012, 26(9):525-532.

21. Karelis AD, Pasternyk SM, Messier L, St-Pierre DH, Lavoie JM, Garrel D, Rabasa-Lhoret R: Relationship between insulin sensitivity and the triglyceride-HDL-C ratio in overweight and obese postmenopausal women: a MONET study. Appl Physiol Nutr Metab 2007, 32(6):10891096.

22. Ho Cl, Chen JY, Chen SY, Tsai YW, Weng YM, Tsao YC, Li WC: Relationship between TG/HDL-C ratio and metabolic syndrome risk factors with chronic kidney disease in healthy adult population. Clin Nutr 2015, 34(5):874-880.

23. Shin HG, Kim YK, Kim YH, Jung YH, Kang HC: The Relationship between the Triglyceride to High-Density Lipoprotein Cholesterol Ratio and Metabolic Syndrome. Korean J Fam Med 2017, 38(6):352-357.

24. Aslan Cin NN, Yardimci H, Koc N, Ucakturk SA, Akcil Ok M: Triglycerides/high-density lipoprotein cholesterol is a predictor similar to the triglyceride-glucose index for the diagnosis of metabolic syndrome using Intemational Diabetes Federation criteria of insulin resistance in obese adolescents: a cross-sectional study. J Pediatr Endocrinol Metab 2020, 33(6):777-784.

25. Liu XY, Wu QY, Chen ZH, Yan GY, Lu Y, Dai HJ, Li Y, Yang PT, Yuan H: Elevated triglyceride to high-density lipoprotein cholesterol (TG/HDLC) ratio increased risk of hyperuricemia: a 4-year cohort study in China. Endocrine 2020, 68(1):71-80.

26. Wu KT, Kuo PL, Su SB, Chen YY, Yeh ML, Huang Cl, Yang JF, Lin Cl, Hsieh MH, Hsieh MY et al: Nonalcoholic fatty liver disease severity is associated with the ratios of total cholesterol and triglycerides to high-density lipoprotein cholesterol. J Clin Lipido/ 2016, 10(2):420-425 e421.

27. Fan N, Peng L, Xia Z, Zhang L, Song Z, Wang Y, Peng Y: Triglycerides to high-density lipoprotein cholesterol ratio as a surrogate for nonalcoholic fatty liver disease: a cross-sectional study. Lipids Health Dis 2019, 18(1):39.

28. Chen C, Dai JL: Triglyceride to high-density lipoprotein cholesterol (HDL-C) ratio and arterial stiffness in Japanese population: a secondary analysis based on a cross-sectional study. Lipids Health Dis 2018, 17(1):130.

29. Chung TH, Shim JY, Kwon YJ, Lee YJ: High triglyceride to high-density lipoprotein cholesterol ratio and arterial stiffness in postmenopausal Korean women. J Clin Hypertens (Greenwich) 2019, 21(3):399-404.

30. Shishehbor MH, Hoogwerf BJ, Lauer MS: Association of triglyceride-to-HDL cholesterol ratio with heart rate recovery. Diabetes Care 2004, 27(4):936-941.

31. Li X, Deng YP, Yang M, Wu YW, Sun SX, Sun JZ: Triglyceride to high-density lipoprotein cholesterol ratio and carotid intima-medial thickness in Chinese adolescents with newly diagnosed type 2 diabetes mellitus. Pediatr Diabetes 2016, 17(2):87-92.

32. Turak O, Afsar B, Ozcan F, Oksuz F, Mendi MA, Yayla C, Covic A, Bertelsen N, Kanbay M: The Role of Plasma Triglyceride/High-Density Lipoprotein Cholesterol Ratio to Predict New Cardiovascular Events in Essential Hypertensive Patients. J Clin Hypertens (Greenwich) 2016, 18(8):772-777.

33. Park JH, Lee J, Ovbiagele B: Nontraditional serum lipid variables and recurrent stroke risk. Stroke 2014, 45(11):3269-3274.

34. Chen Z, Chen G, Qin H, Cai Z, Huang J, Chen H, Wu W, Chen Z, Wu S, Chen Y: Higher triglyceride to high-density lipoprotein cholesterol ratio increases cardiovascular risk: 10-year prospective study in a cohort of Chinese adults. J Diabetes Investig 2020, 11(2):475-481.

35. Chang TI, Streja E, Soohoo M, Kim TW, Rhee CM, Kovesdy CP, Kashyap ML, Vaziri ND, Kalantar-Zadeh K, Moradi H: Association of Serum Triglyceride to HDL Cholesterol Ratio with All-Cause and Cardiovascular Mortality in Incident Hemodialysis Patients. Clin J Am SoC Nephrol 2017, 12(4):591-602.

36. Bittner V, Johnson BD, Zineh I, Rogers WJ, Vido D, Marroquin OC, Bairey-Merz CN, Sopko G: The triglyceride/high-density lipoprotein cholesterol ratio predicts all-cause mortality in women with suspected myocardial ischemia: a report from the Women's Ischemia Syndrome Evaluation (WISE). Am Heart J 2009, 157(3):548-555.

37. Wan K, Zhao J, Huang H, Zhang Q, Chen X, Zeng Z, Zhang L, Chen Y: The association between triglyceride/high-density lipoprotein cholesterol ratio and all-cause mortality in acute coronary syndrome after coronary revascularization. PLoS One 2015, $10(4):$ e0123521.

38. Su YM, Zhang R, Xu RF, Wang HL, Geng HH, Pan M, Qu YY, Zuo WJ, Ji ZJ, Ma GS: Triglyceride to high-density lipoprotein cholesterol ratio as a risk factor of repeat revascularization among patients with acute coronary syndrome after first-time percutaneous coronary intervention. J Thorac Dis 2019, 11(12):5087-5095.

39. Matsumoto I, Misaki A, Kurozumi M, Nanba T, Takagi Y: Impact of nonfasting triglycerides/high-density lipoprotein cholesterol ratio on secondary prevention in patients treated with statins. $J$ Cardiol 2018, 71(1):10-15.

40. Sultani R, Tong DC, Peverelle M, Lee YS, Baradi A, Wilson AM: Elevated Triglycerides to High-Density Lipoprotein Cholesterol (TG/HDL-C) Ratio Predicts Long-Term Mortality in High-Risk Patients. Heart Lung Circ 2020, 29(3):414-421. 
41. Prasad M, Sara J, Widmer RJ, Lennon R, Lerman LO, Lerman A: Triglyceride and Triglyceride/ HDL (High Density Lipoprotein) Ratio Predict Major Adverse Cardiovascular Outcomes in Women With Non-Obstructive Coronary Artery Disease. J Am Heart Assoc 2019, 8(9):e009442.

42. Dai XY, Zheng YY, Tang JN, Yang XM, Guo QQ, Zhang JC, Cheng MD, Song FH, Liu ZY, Wang K et al: Triglyceride to high-density lipoprotein cholesterol ratio as a predictor of long-term mortality in patients with coronary artery disease after undergoing percutaneous coronary intervention: a retrospective cohort study. Lipids Health Dis 2019, 18(1):210.

43. Wan GX, Xia WB, Ji LH, Qin HL, Zhang YG: Triglyceride to high density lipoprotein cholesterol ratio may serve as a useful predictor of major adverse coronary event in female revascularized ST-elevation myocardial infarction. Clin Chim Acta 2018, 485:166-172.

44. He S, Wang S, Chen X, Jiang L, Peng Y, Li L, Wan L, Cui K: Higher ratio of triglyceride to high-density lipoprotein cholesterol may predispose to diabetes mellitus: 15-year prospective study in a general population. Metabolism 2012, 61(1):30-36.

45. Vega GL, Barlow CE, Grundy SM, Leonard D, DeFina LF: Triglyceride-to-high-density-lipoprotein-cholesterol ratio is an index of heart disease mortality and of incidence of type 2 diabetes mellitus in men. J Investig Med 2014, 62(2):345-349.

46. Chen Z, Hu H, Chen M, Luo X, Yao W, Liang Q, Yang F, Wang X: Association of Triglyceride to high-density lipoprotein cholesterol ratio and incident of diabetes mellitus: a secondary retrospective analysis based on a Chinese cohort study. Lipids Health Dis 2020, 19(1):33.

47. Zheng D, Li H, Ai F, Sun F, Singh M, Cao X, Jiang J, He Y, Tang Z, Guo X: Association between the triglyceride to high-density lipoprotein cholesterol ratio and the risk of type 2 diabetes mellitus among Chinese elderly: the Beijing Longitudinal Study of Aging. BMJ Open Diabetes Res Care 2020, 8(1).

48. Cheng C, Liu Y, Sun X, Yin Z, Li H, Zhang M, Zhang D, Wang B, Ren Y, Zhao Y et al: Dose-response association between the triglycerides: High-density lipoprotein cholesterol ratio and type 2 diabetes mellitus risk: The rural Chinese cohort study and meta-analysis. $J$ Diabetes 2019, 11(3):183-192.

49. Lee MY, Hsiao PJ, Huang JC, Hsu WH, Chen SC, Chang JM, Shin SJ: Associations between Triglyceride/High-Density Lipoprotein Cholesterol Ratio and Micro- and Macroangiopathies in Type 2 Diabetes Mellitus. Endocr Pract 2018, 24(7):615-621.

50. Yang SH, Du Y, Li XL, Zhang Y, Li S, Xu RX, Zhu CG, Guo YL, Wu NQ, Qing P et al: Triglyceride to High-Density Lipoprotein Cholesterol Ratio and Cardiovascular Events in Diabetics With Coronary Artery Disease. Am J Med Sci 2017, 354(2):117-124.

51. Sone H, Nakagami T, Nishimura R, Tajima N, Group MS: Comparison of lipid parameters to predict cardiovascular events in Japanese mild-to-moderate hypercholesterolemic patients with and without type 2 diabetes: Subanalysis of the MEGA study. Diabetes Res Clin Pract 2016, 113:14-22.

52. Miller M, Cannon CP, Murphy SA, Qin J, Ray KK, Braunwald E, Investigators PI-T: Impact of triglyceride levels beyond low-density lipoprotein cholesterol after acute coronary syndrome in the PROVE IT-TIMI 22 trial. J Am Coll Cardio/ 2008, 51(7):724-730.

53. Bos G, Dekker JM, Nijpels G, de Vegt F, Diamant M, Stehouwer CD, Bouter LM, Heine RJ, Hoorn S: A combination of high concentrations of serum triglyceride and non-high-density-lipoprotein-cholesterol is a risk factor for cardiovascular disease in subjects with abnormal glucose metabolism-The Hoorn Study. Diabetologia 2003, 46(7):910-916.

54. Edwards MK, Blaha MJ, Loprinzi PD: Atherogenic Index of Plasma and Triglyceride/High-Density Lipoprotein Cholesterol Ratio Predict Mortality Risk Better Than Individual Cholesterol Risk Factors, Among an Older Adult Population. Mayo Clin Proc 2017, 92(4):680-681.

55. da Luz PL, Favarato D, Faria-Neto JR, Jr., Lemos P, Chagas AC: High ratio of triglycerides to HDL-cholesterol predicts extensive coronary disease. Clinics (Sao Paulo) 2008, 63(4):427-432.

56. Yunke Z, Guoping L, Zhenyue C: Triglyceride-to-HDL cholesterol ratio. Predictive value for CHD severity and new-onset heart failure. Herz 2014, 39(1):105-110.

57. Takata K, Kataoka Y, Andrews J, Puri R, Hammadah M, Duggal B, Kapadia SR, Tuzcu EM, Nissen SE, Nicholls SJ: Triglyceride-to-HighDensity Lipoprotein Cholesterol Ratio and Vulnerable Plaque Features With Statin Therapy in Diabetic Patients With Coronary Artery Disease: Frequency-Domain Optical Coherence Tomography Analysis. JACC Cardiovasc Imaging 2018, 11(11):1721-1723.

58. Eeg-Olofsson K, Gudbjornsdottir S, Eliasson B, Zethelius B, Cederholm J, Ndr: The triglycerides-to-HDL-cholesterol ratio and cardiovascular disease risk in obese patients with type 2 diabetes: an observational study from the Swedish National Diabetes Register (NDR). Diabetes Res Clin Pract 2014, 106(1):136-144.

59. Tohidi M, Hatami M, Hadaegh F, Safarkhani M, Harati H, Azizi F: Lipid measures for prediction of incident cardiovascular disease in diabetic and non-diabetic adults: results of the $\mathbf{8 . 6}$ years follow-up of a population based cohort study. Lipids Health Dis $2010,9: 6$.

60. Moriyama K: The Association between the Triglyceride to High-density Lipoprotein Cholesterol Ratio and Low-density Lipoprotein Subclasses. Intern Med 2020, 59(21):2661-2669.

61. Quispe R, Manalac RJ, Faridi KF, Blaha MJ, Toth PP, Kulkarni KR, Nasir K, Virani SS, Banach M, Blumenthal RS et al: Relationship of the triglyceride to high-density lipoprotein cholesterol (TG/HDL-C) ratio to the remainder of the lipid profile: The Very Large Database of 
Lipids-4 (VLDL-4) study. Atherosclerosis 2015, 242(1):243-250.

62. Zonszein J, Lombardero M, Ismail-Beigi F, Palumbo P, Foucher S, Groenewoud Y, Cushing G, Wajchenberg B, Genuth S, Bari DSG:

Triglyceride High-Density Lipoprotein Ratios Predict Glycemia-Lowering in Response to Insulin Sensitizing Drugs in Type 2 Diabetes: A Post Hoc Analysis of the BARI 2D. J Diabetes Res 2015, 2015:129891.

\section{Tables}

Table 1 Baseline characteristics of 3 groups

\begin{tabular}{|c|c|c|c|c|}
\hline Variable & Tertile $1(n=693)$ & Tertile 2 ( $n=693)$ & Tertile $3(n=694)$ & $P$ value \\
\hline Age, years & $66.2 \pm 6.7$ & $66.2 \pm 6.9$ & $66.1 \pm 6.7$ & 0.870 \\
\hline Male & $400(57.7)$ & $391(56.4)$ & $376(54.2)$ & 0.405 \\
\hline Duration of diabetes & $9.5 \pm 7.9$ & $9.8 \pm 7.5$ & $9.9 \pm 7.7$ & 0.636 \\
\hline Smoker & $265(38.2)$ & $289(41.7)$ & $267(38.5)$ & 0.337 \\
\hline Hypertension & $529(76.3)$ & $531(76.6)$ & $525(75.6)$ & 0.909 \\
\hline Previous MI & $80(11.5)$ & $86(12.4)$ & $91(13.1)$ & 0.674 \\
\hline Previous PCl & $153(22.1)$ & $130(18.8)$ & $132(19.0)$ & 0.228 \\
\hline Previous CABG & $24(3.5)$ & $25(3.6)$ & $32(4.6)$ & 0.479 \\
\hline Previous stroke & $157(22.7)$ & $143(20.6)$ & 134(19.3) & 0.303 \\
\hline $\mathrm{BMl}, \mathrm{kg} / \mathrm{m} 2$ & $25.3 \pm 2.9$ & $25.5 \pm 2.7$ & $25.7 \pm 2.8$ & 0.020 \\
\hline LVEF & $58 \pm 8$ & $58 \pm 9$ & $58 \pm 9$ & 0.193 \\
\hline Clinical presentation & & & & 0.353 \\
\hline SAP & 131(18.9) & $111(16.0)$ & $118(17.0)$ & \\
\hline ACS & $562(81.1)$ & $582(84.0)$ & $576(83.0)$ & \\
\hline Left main disease & $69(10.0)$ & $78(11.3)$ & 71(10.2) & 0.707 \\
\hline Multi-vessel disease & $561(81.0)$ & $563(81.2)$ & $570(82.1)$ & 0.841 \\
\hline Treatment strategy & & & & 0.880 \\
\hline MT & 219(31.6) & 202(29.1) & $214(30.8)$ & \\
\hline $\mathrm{PCl}$ & $399(57.6)$ & $410(59.2)$ & $406(58.5)$ & \\
\hline CABG & $73(10.5)$ & $79(11.4)$ & 73(10.5) & \\
\hline \multicolumn{5}{|l|}{ Laboratory findings } \\
\hline FPG, mmol/L, & $7.9 \pm 2.9$ & $8.0 \pm 3.0$ & $8.2 \pm 3.3$ & 0.077 \\
\hline $\mathrm{HbA} 1 \mathrm{c}, \%$ & $7.4 \pm 1.3$ & $7.5 \pm 1.4$ & $7.7 \pm 1.6$ & 0.002 \\
\hline $\mathrm{TC}, \mathrm{mmol} / \mathrm{L}$ & $4.58 \pm 1.16$ & $4.45 \pm 1.07$ & $4.31 \pm 1.10$ & $<0.001$ \\
\hline $\mathrm{TG}, \mathrm{mmol} / \mathrm{L}$ & $1.01(0.81-1.21)$ & $1.52(1.28-1.79)$ & $2.41(1.94-3.06)$ & $<0.001$ \\
\hline LDL-C, mmol/L & $2.96 \pm 1.02$ & $2.96 \pm 0.94$ & $2.85 \pm 0.95$ & 0.053 \\
\hline HDL-C, mmol/L & $1.20 \pm 0.29$ & $1.01 \pm 0.23$ & $0.92 \pm 0.22$ & $<0.001$ \\
\hline TG/HDL-C ratio & $0.88 \pm 0.21$ & $1.54 \pm 0.20$ & $3.09 \pm 1.62$ & $<0.001$ \\
\hline Uric acid, umol/L & $305.4 \pm 93.4$ & $321.7 \pm 92.0$ & $331.1 \pm 100.3$ & $<0.001$ \\
\hline hs-CRP, mg/L & $1.50(0.59-4.76)$ & $1.83(0.79-4.64)$ & $2.08(0.94-4.82)$ & $<0.001$ \\
\hline eGFR, $\mathrm{mL} / \mathrm{min}$ & $94.0 \pm 24.8$ & $92.3 \pm 23.8$ & $89.6 \pm 24.6$ & 0.003 \\
\hline
\end{tabular}




\begin{tabular}{|lllll|}
\hline Variable & Tertile 1 $(\mathbf{n = 6 9 3 )}$ & Tertile 2 $(\mathbf{n = 6 9 3 )}$ & Tertile 3 $(\mathbf{n = 6 9 4 )}$ & P value \\
\hline Medications at discharge & & & & \\
\hline Aspirin & $668(96.4)$ & $673(97.1)$ & $675(97.3)$ & 0.605 \\
\hline Clopidogrel/Ticagrelor & $559(80.7)$ & $574(82.8)$ & $581(83.7)$ & 0.307 \\
\hline B-blocker & $450(64.9)$ & $461(66.5)$ & $456(65.7)$ & 0.824 \\
\hline ACEl/ARB & $404(58.3)$ & $381(55.0)$ & $407(58.6)$ & 0.313 \\
\hline CCB & $174(25.1)$ & $199(28.7)$ & $203(29.3)$ & 0.172 \\
\hline Nitrate & $382(55.1)$ & $379(54.7)$ & $391(56.3)$ & 0.814 \\
\hline Insulin & $284(41.0)$ & $280(40.4)$ & $273(39.3)$ & 0.818 \\
\hline
\end{tabular}

Data are expressed as mean \pm SD, medians with interquartile ranges or percentage.

$M I$ myocardial infarction, $P C /$ percutaneous coronary intervention, $C A B G$ coronary artery bypass graft, $B M I$ body mass index, $L V E F$ left ventricle ejection fraction, $S A P$ stable angina pectoris, ACS acute coronary syndrome, MT medical therapy, FPG fasting plasma glucose, $H b A 1 c$ Hemoglobin A1c, TC total cholesterol, TG triglycerides, $L D L-C$ low-density lipoprotein cholesterol, $H D L-C$ high-density lipoprotein cholesterol, hs-CRP high-sensitivity C-reactive protein, eGFR estimated glomerular filtration rate, $A C E /$ angiotensin II coenzyme inhibitor, $A R B$ angiotensin II receptor blocker, $C C B$ calcium channel blocker; $S D$, standard deviation.

Table2 Cox Regression Models in Predicting all-cause mortality and cardiovascular mortality according to TG/HDL-C ratio at baseline

\begin{tabular}{|c|c|c|c|c|c|c|c|}
\hline \multirow[b]{2}{*}{ End point } & \multirow[b]{2}{*}{$\begin{array}{l}\text { TG/HDL- } \\
\text { C ratio }\end{array}$} & \multirow[b]{2}{*}{$\begin{array}{l}\text { Events, } \\
\text { n/Total (\%) }\end{array}$} & \multicolumn{5}{|l|}{ HR (95\%Cl) } \\
\hline & & & $\begin{array}{l}\text { Unadjusted } \\
\text { Model }\end{array}$ & Model1 & Model2 & Model3 & Model4 \\
\hline All-cause & Tertile1 & $46 / 693(6.6)$ & 1.00(reference) & 1.00(reference) & 1.00(reference) & 1.00(reference) & 1.00(reference) \\
\hline \multirow[t]{3}{*}{ mortality } & Tertile2 & 70/693(101.) & $\begin{array}{l}1.54(1.06- \\
2.23) *\end{array}$ & $\begin{array}{l}1.48(1.02- \\
2.15) *\end{array}$ & $\begin{array}{l}1.46(1.00- \\
2.12)\end{array}$ & $\begin{array}{l}1.19(0.81- \\
1.75)\end{array}$ & $\begin{array}{l}1.20(0.81- \\
1.76)\end{array}$ \\
\hline & \multirow{2}{*}{$\begin{array}{l}\text { Tertil3 } \\
\text { Per 1-SD }\end{array}$} & \multirow[t]{2}{*}{$93 / 694(13.4)$} & $\begin{array}{l}2.09(1.47- \\
2.98) * \star\end{array}$ & $\begin{array}{l}2.08(1.46- \\
2.96) * \star\end{array}$ & $\begin{array}{l}1.99(1.39- \\
2.84) * *\end{array}$ & $\begin{array}{l}1.49(1.03- \\
2.15) *\end{array}$ & $\begin{array}{l}1.50(1.04- \\
2.18) \star\end{array}$ \\
\hline & & & $\begin{array}{l}1.17(1.10- \\
1.24) * \star\end{array}$ & $\begin{array}{l}1.23(1.15- \\
1.32) * \star\end{array}$ & $\begin{array}{l}1.26(1.17- \\
1.35) * \star\end{array}$ & $\begin{array}{l}1.21(1.11- \\
1.31) * *\end{array}$ & $\begin{array}{l}1.21(1.11- \\
1.31) * *\end{array}$ \\
\hline Cardiovascular & Tertile1 & 27/693(3.9) & 1.00 (reference) & 1.00(reference) & 1.00 (reference) & 1.00(reference) & 1.00(reference) \\
\hline \multirow[t]{3}{*}{ mortality } & Tertile2 & $43 / 693(6.2)$ & $\begin{array}{l}1.98(1.28- \\
3.08) *\end{array}$ & $\begin{array}{l}1.60(0.99- \\
2.60)\end{array}$ & $\begin{array}{l}1.58(0.98- \\
2.57)\end{array}$ & $\begin{array}{l}1.41(0.86- \\
2.31)\end{array}$ & $\begin{array}{l}1.41(0.86- \\
2.32)\end{array}$ \\
\hline & \multirow{2}{*}{$\begin{array}{l}\text { Tertile3 } \\
\text { Per 1-SD }\end{array}$} & \multirow[t]{2}{*}{$66 / 694(9.5)$} & $\begin{array}{l}2.45(1.60- \\
3.75) \star \star\end{array}$ & $\begin{array}{l}2.53(1.62- \\
3.97) \star *\end{array}$ & $\begin{array}{l}2.47(1.57- \\
3.88) * \star\end{array}$ & $\begin{array}{l}1.97(1.23- \\
3.14) *\end{array}$ & $\begin{array}{l}1.99(1.25- \\
3.18) *\end{array}$ \\
\hline & & & $\begin{array}{l}1.22(1.16- \\
1.29) \star \star\end{array}$ & $\begin{array}{l}1.27(1.20- \\
1.36) \star \star\end{array}$ & $\begin{array}{l}1.30(1.22- \\
1.39) \star *\end{array}$ & $\begin{array}{l}1.28(1.19- \\
1.38) \star \star\end{array}$ & $\begin{array}{l}1.28(1.19- \\
1.37) \text { ** }\end{array}$ \\
\hline
\end{tabular}

Model1 was adjusted for age, male, smoker, duration of diabetes, hypertension, previous MI, previous PCl, previous CABG, previous stroke, BMI; Model 2 was adjusted for model 2 covariates plus LVEF, ACS, left main disease, multi-vessel disease, treatment;Model3 was adjusted for model 3 covariates plus FPG, HbA1c, TC, LDL, Uric acid, hs-CRP, eGFR; Model 4 was adjusted for model 4 covariates plus aspirin, clopidogrel/ticagrelor, $\beta$-blocker, ACEI/ARB,CCB, nitrate and insulin. TG triglycerides, $H D L-C$ high-density lipoprotein cholesterol, $H R$ hazard ratio, $C /$ confidential interval, $S D$ standard deviation. ${ }^{*} \mathrm{P}<0.05 ; * \star \mathrm{P}<0.001$.

Table3 Sensitivity analysis of the association of TG/HDL-C ratio per 1-SD with mortality after separate adjustment for each of the other significant variables 


\begin{tabular}{|c|c|c|c|c|c|c|}
\hline \multirow{3}{*}{$\begin{array}{l}\text { Adjustment } \\
\text { variable }\end{array}$} & \multicolumn{3}{|c|}{ Multivariable analysis for all-cause mortality } & \multicolumn{3}{|c|}{ Multivariable analysis for cardiac mortality } \\
\hline & \multicolumn{3}{|c|}{ HR for TG/HDL-C per } & \multicolumn{3}{|c|}{ HR for TG/HDL-C per } \\
\hline & $1-\mathrm{SD}$ & $95 \% \mathrm{Cl}$ & $\mathrm{P}$ value & 1-SD & $95 \% \mathrm{Cl}$ & $P$ value \\
\hline Age & 1.20 & $1,13-1,28$ & $<0.001$ & 1.26 & $1.19-1.33$ & $<0.001$ \\
\hline Previous $\mathrm{PCl}$ & 1.18 & $1.11-1.25$ & $<0.001$ & 1.24 & $1.17-1.32$ & $<0.001$ \\
\hline LVEF & 1.20 & $1.12-1.27$ & $<0.001$ & 1.26 & $1.19-1.34$ & $<0.001$ \\
\hline Left main disease & 1.17 & $1.10-1.24$ & $<0.001$ & 1.23 & $1.16-1.30$ & $<0.001$ \\
\hline Multi-vessel disease & 1.17 & $1.10-1.24$ & $<0.001$ & 1.22 & $1.16-1.29$ & $<0.001$ \\
\hline FPG & 1.17 & $1.10-1.24$ & $<0.001$ & 1.23 & $1.17-1.30$ & $<0.001$ \\
\hline eGFR & 1.15 & $1.08-1.23$ & $<0.001$ & 1.21 & $1.14-1.28$ & $<0.001$ \\
\hline
\end{tabular}

$P C /$ percutaneous coronary intervention, $L V E F$ left ventricle ejection fraction, FPG fasting plasma glucose, eGFR estimated glomerular filtration rate, $T G$ triglycerides, $H D L-C$ high-density lipoprotein cholesterol, $H R$ hazard ratio, $C /$ confidential interval, $S D$ standard deviation.

Table4 Evaluation of Predictive Models for all-cause and cardiovascular mortality

\begin{tabular}{|c|c|c|c|c|c|c|c|}
\hline Endpoint & & C-Statistic & $\begin{array}{l}P \\
\text { value }\end{array}$ & NRI (95\%Cl) & $\begin{array}{l}P \\
\text { value }\end{array}$ & IDI (95\%Cl) & $\begin{array}{l}P \\
\text { value }\end{array}$ \\
\hline \multirow{6}{*}{$\begin{array}{l}\text { All-cause } \\
\text { mortality } \\
\text { Cardiovascular } \\
\text { mortality }\end{array}$} & \multirow{3}{*}{$\begin{array}{l}\text { Original model } \\
\text { Original model+TG/HDL- } \\
\text { C ratio }\end{array}$} & $0.799(0.766-$ & Ref. & & Ref. & & Ref. \\
\hline & & \multirow{2}{*}{$\begin{array}{l}0.813(0.780- \\
0.845)\end{array}$} & 0.018 & \multirow{2}{*}{$\begin{array}{l}0.315(0.175- \\
0.457)\end{array}$} & $<0.001$ & $0.012(0.004-$ & 0.003 \\
\hline & & & Ref. & & \multirow{3}{*}{$\begin{array}{l}\text { Ref. } \\
<0.001\end{array}$} & & \multirow{2}{*}{$\begin{array}{l}\text { Ref. } \\
<0.001\end{array}$} \\
\hline & & $0.769(0.727-$ & 0.001 & & & & \\
\hline & \multirow{2}{*}{$\begin{array}{l}\text { Original model+TG/HDL- } \\
\mathrm{C} \text { ratio }\end{array}$} & $0.812)$ & & \multirow{2}{*}{$\begin{array}{l}0.442(0.270- \\
0.613)\end{array}$} & & \multirow[t]{2}{*}{$\begin{array}{l}0.039(0.023- \\
0.055)\end{array}$} & \\
\hline & & $\begin{array}{l}0.810(0.771- \\
0.849)\end{array}$ & & & & & \\
\hline
\end{tabular}

Original model included age, previous PCI, LVEF, left main disease, multi-vessel disease, FPG and eGFR. TG triglycerides, $H D L-C$ high-density lipoprotein cholesterol, $N R I$, net reclassification improvement; IDI, integrated discrimination improvement, $C /$ confidential interval.

Table5 All-cause and cardiovascular mortality in various subgroups of patients 


\begin{tabular}{|c|c|c|c|c|c|c|c|c|}
\hline \multirow[b]{3}{*}{ Variables } & \multicolumn{3}{|c|}{ All-cause mortality } & & \multicolumn{4}{|c|}{ Cardiovascular mortality } \\
\hline & \multicolumn{2}{|c|}{ TG/HDL-C ratio } & & & \multicolumn{3}{|c|}{ TG/HDL-C ratio } & \multirow[b]{2}{*}{$\begin{array}{l}\text { P for } \\
\text { interaction }\end{array}$} \\
\hline & $\leq 1.77$ & $>1.77$ & $\mathrm{HR}(95 \% \mathrm{Cl})$ & $\begin{array}{l}\text { P for } \\
\text { interaction }\end{array}$ & $\leq 1.57$ & $>1.57$ & $\mathrm{HR}(95 \% \mathrm{Cl})$ & \\
\hline All patients & $99 / 1274$ & $110 / 806$ & $\begin{array}{l}1.821(1.388- \\
2.389)\end{array}$ & & $36 / 1083$ & $100 / 997$ & $\begin{array}{l}3.124(2.135- \\
4.573)\end{array}$ & \\
\hline Sex & & & & 0.985 & & & & 0.552 \\
\hline Women & $45 / 555$ & $47 / 358$ & $\begin{array}{l}1.661 \rrbracket 1.104- \\
2.500 \rrbracket\end{array}$ & & $15 / 462$ & $49 / 451$ & $\begin{array}{l}3.453(1.936- \\
6.156)\end{array}$ & \\
\hline Men & $54 / 719$ & $63 / 448$ & $\begin{array}{l}1.956 \rrbracket 1.360- \\
2.813 \rrbracket\end{array}$ & & $21 / 621$ & $51 / 546$ & $\begin{array}{l}2.867(1.725- \\
4.766)\end{array}$ & \\
\hline Smoker & & & & 0.173 & & & & 0.537 \\
\hline No & $61 / 770$ & $57 / 489$ & $\begin{array}{l}1.498 \rrbracket 1.044- \\
2.150 \rrbracket\end{array}$ & & $21 / 646$ & $59 / 613$ & $\begin{array}{l}3.041(1.848- \\
5.003)\end{array}$ & \\
\hline Yes & $38 / 504$ & $53 / 317$ & $\begin{array}{l}2.360 \rrbracket 1.556- \\
3.580 \rrbracket\end{array}$ & & $15 / 437$ & $41 / 384$ & $\begin{array}{l}3.262(1.805- \\
5.893)\end{array}$ & \\
\hline $\mathrm{BMI}>28$ & & & & 0.741 & & & & 0.285 \\
\hline No & $79 / 1058$ & $91 / 655$ & $\begin{array}{l}1.930(1.428- \\
2.609)\end{array}$ & & $33 / 905$ & $83 / 808$ & $\begin{array}{l}2.918(1.949- \\
4.367)\end{array}$ & \\
\hline Yes & $20 / 216$ & $19 / 151$ & $\begin{array}{l}1.409(0.752- \\
2.640)\end{array}$ & & $3 / 178$ & $17 / 189$ & $\begin{array}{l}5.504(2.613- \\
8.783)\end{array}$ & \\
\hline $\begin{array}{l}\text { Duration of } \mathrm{DM}>10 \\
\text { years }\end{array}$ & & & & 0.090 & & & & 0.442 \\
\hline No & $53 / 773$ & $63 / 491$ & $\begin{array}{l}1.933 \rrbracket 1.341- \\
2.785 \rrbracket\end{array}$ & & $17 / 654$ & $62 / 610$ & $\begin{array}{l}4.052(2.369- \\
6.929)\end{array}$ & \\
\hline Yes & $46 / 501$ & $47 / 315$ & $\begin{array}{l}1.697 \rrbracket 1.130- \\
2.548 \rrbracket\end{array}$ & & $19 / 429$ & $38 / 387$ & $\begin{array}{l}2.291(1.321- \\
3.973)\end{array}$ & \\
\hline ACS & & & & 0.438 & & & & 0.346 \\
\hline No & $16 / 241$ & $15 / 119$ & $\begin{array}{l}1.973 \rrbracket 0.975- \\
3.990 \rrbracket\end{array}$ & & $4 / 241$ & $12 / 119$ & $\begin{array}{l}6.312(2.036- \\
9.587)\end{array}$ & \\
\hline Yes & $83 / 1033$ & $95 / 687$ & $\begin{array}{l}1.783 \rrbracket 1.328- \\
2.394 \rrbracket\end{array}$ & & $32 / 842$ & $88 / 878$ & $\begin{array}{l}2.726(1.819- \\
4.085)\end{array}$ & \\
\hline $\mathrm{HbA} 1 \mathrm{c}>7.0$ & & & & 0.524 & & & & 0.697 \\
\hline No & $41 / 584$ & $46 / 336$ & $\begin{array}{l}2.016 \rrbracket 1.323- \\
3.071 \rrbracket\end{array}$ & & $14 / 499$ & $43 / 421$ & $\begin{array}{l}3.803(2.081- \\
6.952)\end{array}$ & \\
\hline Yes & $58 / 690$ & $64 / 470$ & $\begin{array}{l}1.682 \otimes 1.179- \\
2.400 \rrbracket\end{array}$ & & $22 / 584$ & $57 / 576$ & $\begin{array}{l}2.700(1.651- \\
4.415)\end{array}$ & \\
\hline LDL-C> 1.8 & & & & 0.788 & & & & 0.345 \\
\hline No & $13 / 149$ & $16 / 118$ & & & $8 / 136$ & $11 / 131$ & & \\
\hline Yes & $86 / 1125$ & $94 / 688$ & $\begin{array}{l}1.608(0 . / 73- \\
3.343)\end{array}$ & & $51 / 947$ & $89 / 866$ & $\begin{array}{l}3.853(1.075- \\
13.810)\end{array}$ & \\
\hline & & & $\begin{array}{l}1.854(1.384- \\
2.483)\end{array}$ & & & & $\begin{array}{l}3.064(2.055- \\
4.568)\end{array}$ & \\
\hline Insulin treatment & & & & 0.265 & & & & 0.502 \\
\hline No & $51 / 751$ & $66 / 492$ & $\begin{array}{l}2.065 \rrbracket 1.433- \\
2.976 \rrbracket\end{array}$ & & $18 / 632$ & $61 / 611$ & $\begin{array}{l}3.616 \\
\rrbracket 2.136- \\
6.112 \rrbracket\end{array}$ & \\
\hline Yes & $48 / 523$ & $44 / 314$ & $\begin{array}{l}1.566 \rrbracket 1.040- \\
2.357 \rrbracket\end{array}$ & & $18 / 451$ & $39 / 386$ & 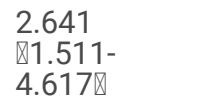 & \\
\hline Revascularization & & & & 0.780 & & & & 0.476 \\
\hline
\end{tabular}




\begin{tabular}{|c|c|c|c|c|c|c|}
\hline No & $31 / 393$ & $35 / 247$ & $\begin{array}{l}1.876(1.157- \\
3.042)\end{array}$ & $9 / 327$ & $37 / 313$ & $\begin{array}{l}4.432(2.139- \\
9.183)\end{array}$ \\
\hline Yes & $68 / 881$ & $75 / 559$ & $\begin{array}{l}1.796(1.293- \\
2.494)\end{array}$ & $27 / 726$ & $63 / 684$ & $\begin{array}{l}2.673(1.703- \\
4.195)\end{array}$ \\
\hline
\end{tabular}

$B M /$ body mass index, $D M$ diabetes mellitus, $A C S$ acute coronary syndrome, $H b A 1 c$ Hemoglobin A1c, $L D L-C$ low-density lipoprotein cholesterol, $H R$ hazard ratio, $C /$ confidential interval

Figures

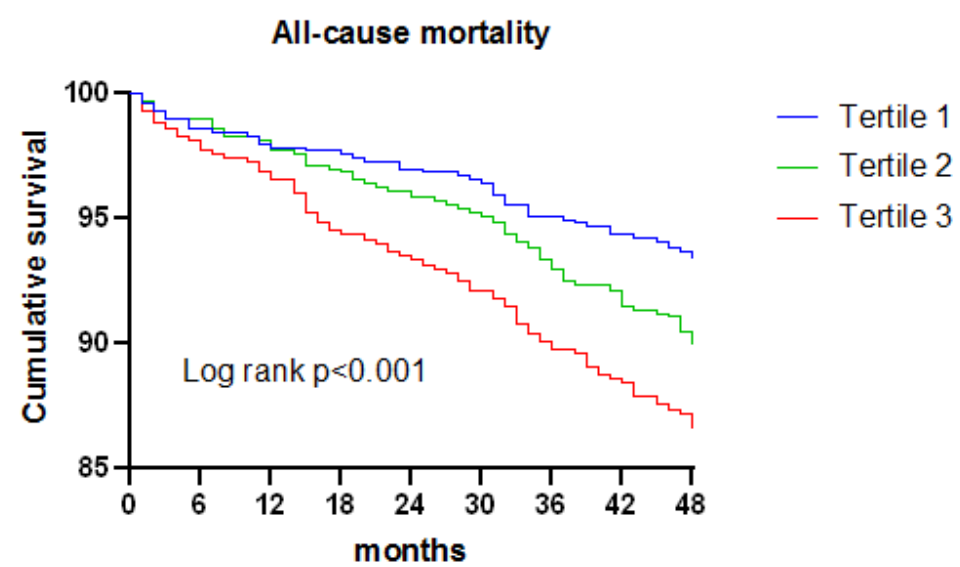

Figure 1

Kaplan-Meier survival curve for all-cause mortality across TG/HDL-C ratio tertiles.

\section{Cardiovascular mortality}

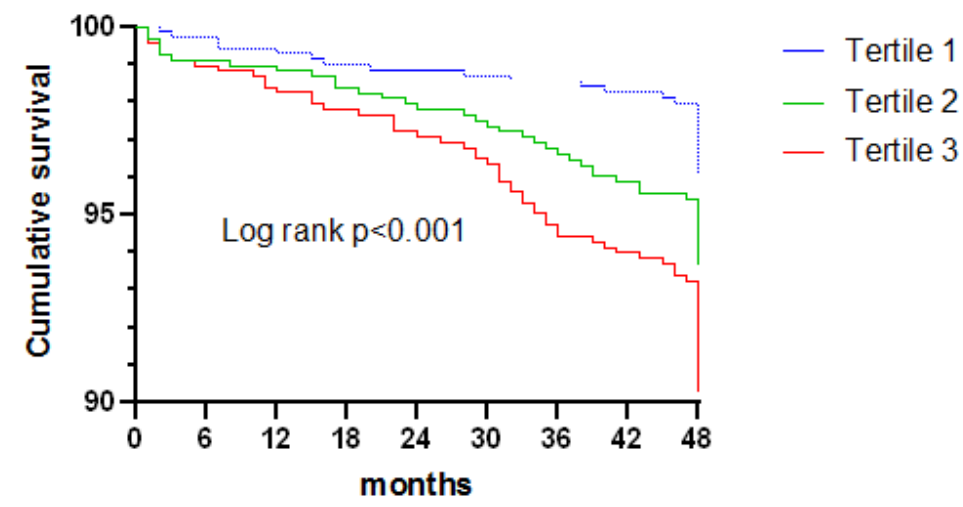

Figure 2

Kaplan-Meier survival curve for cardiovascular mortality across TG/HDL-C ratio tertiles. 